\title{
Distribution of oculocutaneous albinism in Zimbabwe
}

Patricia May Lund

\begin{abstract}
A survey of 1.3 million schoolchildren in Zimbabwe identified a total of 278 pupils with oculocutaneous albinism (OCA), giving a prevalence of 1 in 4728. Pupils with OCA were identified in every province of the country, but the distribution was not even. In certain areas, notably the capital, Harare, and the eastern province of Manicaland, the frequency was significantly higher than in others. Although most of the pupils with albinism belonged to the majority Shona ethnic group, people with OCA were also found among the minority population groups in the country. There were almost twice as many pupils with albinism in rural compared with urban schools (248 $v$ 129). However, the prevalence of OCA was significantly higher in urban than rural areas. These results indicate that data for a country collected solely in urban locations are likely to be biased and emphasise the need for widespread distribution of health and special educational facilities for affected people. (F Med Genet 1996;33:641-644)
\end{abstract}

Key words: albinism; OCA2; Africa.

Oculocutaneous albinism (OCA) is one of the most common recessively inherited conditions in sub-Saharan Africa, resulting in hypopigmentation of the eyes, skin, and hair. Ocular problems, including photophobia, nystagmus, and reduced visual acuity, are associated with all forms of albinism. Tyrosinase negative OCA (also called OCA1) results in little or no pigment production, owing to lack of functional tyrosinase, the key enzyme in the melanin biosynthetic pathway. ${ }^{12}$ In Africa this form is fortunately rare. In a study of more than 600 families over the past 20 years in southern Africa, the OCA1 type of albinism was found to be virtually absent among the negroid population. ${ }^{3}$ Tyrosinase positive OCA (OCA2) is the type most commonly found in southern Africa. Molecular analysis has confirmed that mutations at one particular locus result in OCA 2 in this group. ${ }^{3}$ In these people the enzyme is active, producing some redyellow pheomelanin pigment, giving their hair a sandy colour and eyes a light brown colouration. The pale skin of OCA2 subjects contrasts strikingly with the normal dark pigmentation found in indigenous African populations. Some people with OCA2 develop naevi or lentigines, usually on parts of the skin exposed to the sun. The lack of protective melanin pigment in the skin makes OCA2 subjects prone to skin damage from an early age and increases their risk of developing skin cancer in later life. ${ }^{4-6}$ In addition to the detrimental effect on their health, affected people are often stigmatised in African societies. ${ }^{7-9}$

The $\mathbf{P}$ gene for OCA2, located on chromosome $15,{ }^{10}$ codes for an integral membrane protein with transmembrane domains. ${ }^{11}{ }^{12} \mathrm{Al}-$ though the function of this $\mathrm{P}$ polypeptide remains uncertain, it may be active in transporting tyrosine into melanosomes. It has been suggested that there is locus homogeneity among southern African negroids with OCA2. ${ }^{13}$ The most common mutation so far identified in people with this type of albinism from Africa is a $2.7 \mathrm{~kb}$ deletion that removes an entire exon of the $\mathrm{P}$ gene. ${ }^{314}$

Although OCA2 occurs world wide, it has a relatively high frequency in several African populations. In west Africa estimates range from 1 in 1100 in the Ibo of Nigeria to 1 in 3800 among the Bamlike of the Cameroon. ${ }^{1}$ In southern Africa the frequency varies between different ethnic groups, being highest among the Swazi-Sotho at about 1 in 1500 to $2000,{ }^{15-17}$ and lowest among the Nguni groups at 1 in $4500 .{ }^{15} \mathrm{By}$ contrast, in the USA, the prevalence of OCA2 in whites is only 1 in 36000 and among Afro-Americans 1 in $15000 .^{1}$

As the central southern African country of Zimbabwe has an excellent schooling system, with $34 \%$ of the total population found to be attending school in the 1992 Population Census, ${ }^{18}$ and a reliable postal service, it is an ideal country for gathering population data. An earlier survey found the prevalence of OCA2 among schoolchildren in Harare, the capital city of Zimbabwe, to be 1 in $2833 .{ }^{19}$ As information on the geographical distribution of OCA within African countries is sparse, particularly in rural areas, the survey was extended to cover the whole of Zimbabwe. This report presents details on the prevalence of OCA in the different provinces of the country (fig 1) and compares data from rural and urban areas.

\section{Methods}

The study population for this nationwide survey was drawn from the school going group, in the age range 6 to 23 years. A questionnaire was mailed to the head of every secondary school outside Harare, a total of 1447 schools, and to primary schools in four of the eight provinces outside the capital, a total of 1747 schools. The survey was conducted with the 
permission of the Ministry of Education and Culture as well as the local regional educational authorities. A letter sent with the questionnaire gave a detailed description of the phenotype of affected people (lack of pigmentation of the skin, hair, and eyes) as well as the visual problems associated with albinism. As the appearance of indigenous Africans with OCA contrasts so noticeably with the dark pigmentation of unaffected people, cases could easily be identified by head teachers. It was stressed that responses were required from schools without affected pupils as well as from those having pupils with albinism. The vernacular names for albinism were given, although the questionnaire was in English. The questionnaire asked for information on the pupils in the school (the number of each sex, age range, and ethnicity), the location of the school (urban, rural, or other), and details of any pupils with albinism being educated in the school, including sex, age, and ethnic origin. A second questionnaire was sent to schools failing to respond to the first. Information leaflets on albinism and its management were sent to all schools that had affected pupils.

Although it was not possible to confirm the OCA2 status of all the people in this study, 50 pupils in seven different provinces were examined and found to be OCA2.

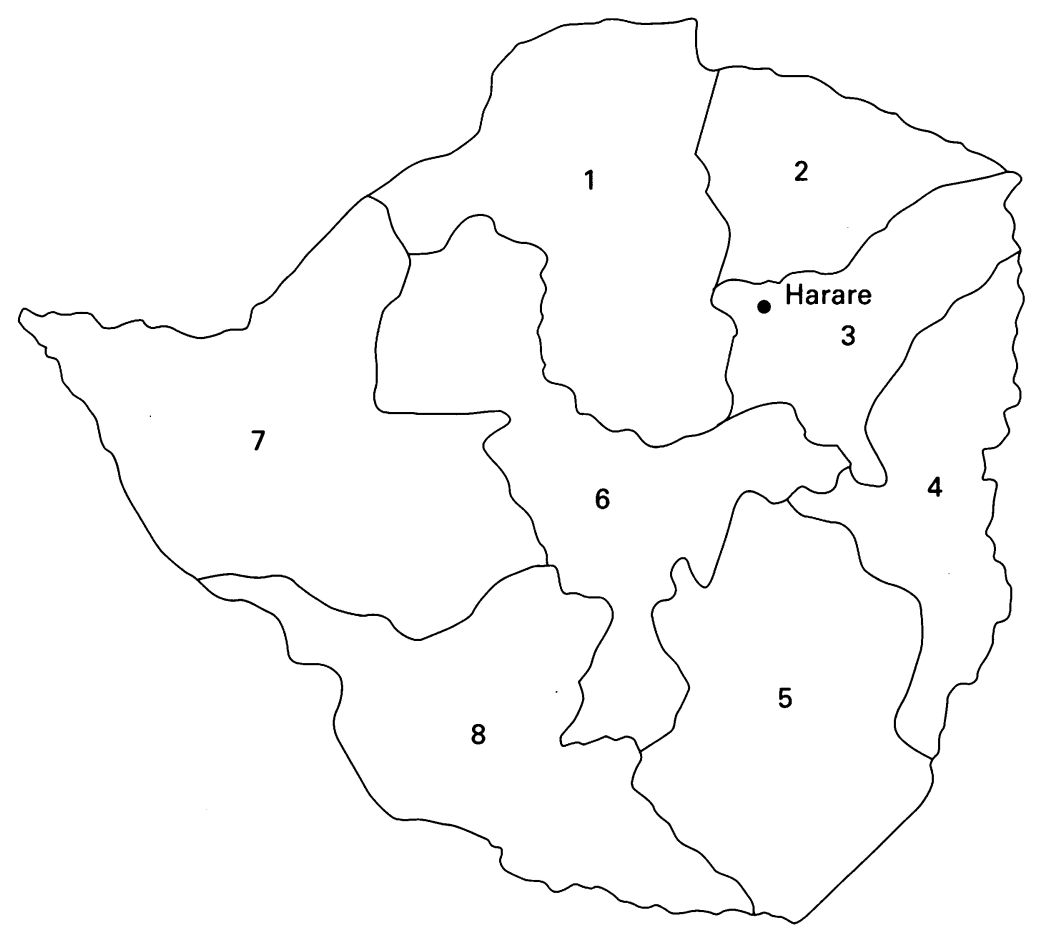

\begin{tabular}{|lll|}
\hline Key & 1 & Mashonaland West \\
& 2 & Mashonaland Central \\
3 & Mashonaland East \\
4 & Manicaland \\
5 & Masvingo \\
6 & Midlands \\
7 & Matabeleland North \\
8 & Matabeleland South
\end{tabular}

Figure 1 The provinces of the central southern African country of Zimbabwe.

\section{Results}

THE SAMPLE

The sample population of 1.3 million schoolchildren aged 6 to 23 years was geographically distributed throughout Zimbabwe. The total population in the 1992 census was 10.4 million, ${ }^{18}$ indicating that about $10 \%$ of the current population of Zimbabwe was included in this survey. Overall, responses were received from 2899 of the $3194(90.8 \%)$ schools sampled. The response rate was uniformly high, ranging from $87.1 \%$ of primaries in Mashonaland East to $95.7 \%$ of secondary schools in Masvingo province. The male to female sex ratio for primary schools was 1.04 (393 105 male, 378602 female, and 1051 pupils of unknown sex). For secondary schools the value was 1.25 (300 031 male, 240294 female, and 1275 pupils of unknown sex), which was significantly different from 1 .

\section{PREVALENCE}

The survey identified 278 pupils with albinism, giving a prevalence of 1 in 4728 (table 1). A total of 157 pupils with albinism were reported in 126 primary schools and 121 affected pupils in 101 secondary schools. Overall $7.8 \%$ of schools responding to the questionnaire were educating pupils with albinism. Assuming Hardy-Weinberg equilibrium, and that the cases of albinism are all of the common OCA2 type, the gene frequency for OCA2 outside the capital was 0.0145 and the carrier rate 1 in 35 . Including data previously collected for schools in Harare province, ${ }^{19}$ the overall prevalence for schoolchildren throughout the country was 1 in 4182 with a total of 384 pupils with albinism identified in a study population of 1605970 . The gene frequency for OCA2 was 0.0155 and the carrier rate 1 in 33 .

The results for the individual provinces presented in table 1 show considerable variation in OCA frequencies. In primary schools prevalence values ranged from 1 in 3843 in Mashonaland East province to 1 in 7539 in Matabeleland South, with an overall value of 1 in 4922, as shown in table 1 . The chi square test, with the Yates correction, indicated significant differences between Matabeleland South and Mashonaland East and West (both $\mathrm{p}<0.025$ ), and between Mashonaland Central and Mashonaland East $(p<0.01)$ which lie next to each other geographically. Harare province had a significantly higher prevalence than three of the four provinces sampled here, namely the neighbouring provinces of Mashonaland Central and West as well as Matabeleland South $(\mathrm{p}<0.01$ for all three). The prevalence values for secondary schools in the eight provinces ranged from 1 in 2956 in Manicaland, on the eastern border of Zimbabwe, to 1 in 7311 in Mashonaland Central. The value for Manicaland was significantly higher than that for both Mashonaland Central $(p<0.025)$ and Mashonaland East $(p<0.05)$, and that for Harare province $^{19}$ higher than for the provinces surrounding the capital, namely Mashonaland East $(p<0.025)$, West, Central, and Midlands (all $\mathrm{p}<0.05)$. 
Table 1 Prevalence of albinism in different provinces in Zimbabwe

\begin{tabular}{lrrlr}
\hline Province & Total pupils & OCA pupils & Prevalence & $\%$ Rural* \\
\hline Primary schools & & & & \\
$\quad$ Mashonaland Central & 172016 & 28 & $1 / 6143$ & 93.6 \\
Mashonaland West & 215401 & 47 & $1 / 4583$ & 84.0 \\
Mashonaland East & 242094 & 63 & $1 / 3843$ & 95.7 \\
Matabeleland South & 143247 & 19 & $1 / 7539$ & 97.1 \\
Total & 772758 & 157 & $1 / 4922$ & 92.2 \\
Harare† & 203795 & 73 & $1 / 2792$ & 4.9 \\
Secondary schools & & & & \\
Mashonaland Central & 36553 & 5 & $1 / 7311$ & 92.1 \\
Mashonaland West & 56592 & 9 & $1 / 6288$ & 73.4 \\
Mashonaland East & 80898 & 13 & $1 / 6223$ & 95.6 \\
Matabeleland South & 33773 & 7 & $1 / 4825$ & 93.4 \\
Matabeleland North & 62690 & 14 & $1 / 4478$ & 40.1 \\
Manicaland & 91619 & 31 & $1 / 2956$ & 89.7 \\
Midlands & 88151 & 17 & $1 / 5185$ & 75.6 \\
Masvingo & 91324 & 25 & $1 / 3653$ & 94.8 \\
Total & 541600 & 121 & $1 / 4476$ & 82.1 \\
Harare & 87817 & 33 & $1 / 2661$ & 1.6 \\
Total (excluding Harare) & 1314358 & 278 & $1 / 4728$ & 88.0 \\
Total for Zimbabwe & 1605970 & 384 & $1 / 4182$ & 73.4 \\
\hline
\end{tabular}

$\star \%$ of pupils attending rural schools.

†Data for Harare province previously collected. ${ }^{19}$

Table 2 Prevalence of albinism in urban and rural dwelling pupils

\begin{tabular}{lccr}
\hline & Urban schools & Rural schools & \multicolumn{1}{l}{ Total } \\
\hline Total population & 421522 & 1164133 & 1585655 \\
Pupils with OCA & 129 & 248 & 377 \\
Prevalence of OCA & $1 / 3268$ & $1 / 4694$ & $1 / 4206$ \\
\hline
\end{tabular}

\section{PUPILS WITH ALBINISM}

A total of 76 male and 81 female primary school pupils with albinism were identified in the four provinces sampled, giving a male to female sex ratio of 0.94 . The respective values for secondary schools in all the provinces outside the capital were 74 male and 47 female with a sex ratio of 1.57 , which is significantly different from the expected ratio of 1 . The sex ratio of 1.18 for all pupils with albinism identified in the survey, however, did not differ significantly from 1 , as expected for an autosomal recessive condition.

The age range of affected pupils in primary schools was 5 to 15 , with a mean of 10.0 years and in secondary schools 13 to 23 , with a mean of 16.3 years. Of the 278 pupils with albinism identified, 231 ( $83.1 \%)$ belonged to the majority Shona ethnic group, $25(9.0 \%)$ to the second most populous group, the Ndebele, with the remainder from the neighbouring countries of Malawi, Zambia, or Mozambique, or the minority ethnic groups within the country, namely the Sotho, Tswana, Tonga, Venda, and Nambia. Data on the ethnic breakdown of pupils were not held by schools, nor were such data collected in the 1992 census. It was therefore not possible to determine the prevalence of OCA in the different ethnic groups within the country in this survey.

URBAN VERSUS RURAL

In order to compare the prevalence in urban and rural areas, data previously collected in schools for Harare province were included, giving a total of 421522 urban and 1164133 rural schoolgoers (table 2). Information on the location of the school, either urban (cities, towns, and periurban) or rural (communal lands and commercial farms), was obtained from 2889 schools surveyed, in addition to 248 schools sampled in the earlier survey of Harare province. Overall $73.4 \%$ of the pupils surveyed attended rural schools (table 1 ).

There were 129 pupils with albinism being educated in an urban setting and 248 attending schools in rural areas (table 2). Overall, 65.8\% of the OCA pupils identified were at rural schools. The values for primary and secondary schools were similar, $65.6 \%$ and $66.0 \%$, respectively. The prevalence of 1 in 3268 in urban areas was significantly greater than the value of 1 in 4694 for rural areas $(p<<0.01)$.

\section{Discussion}

There are three major cultural groups in the grasslands and coastal belt of the eastern part of southern Africa, which includes Zimbabwe, namely the Shona, Sotho, and Nguni. ${ }^{20}$ They are distinguished chiefly on linguistic grounds, although they all speak Bantu languages. The overall prevalence of 1 in 4182 for OCA in Zimbabwe, which is predominantly Shona, is similar to the value of 1 in 4459 reported for the Zulu (Nguni) ethnic group in Soweto, South Africa. ${ }^{15}$ Both the major ethnic groups in Zimbabwe, the Shona and Ndebele, as well as the Zulu, prohibit marriages between close relatives. This contrasts with groups such as the Sotho and Tswana where customs favour close alliances such as cousin marriages and albinism is more prevalent, with a frequency as high as 1 in 1523 in the northern Sotho. ${ }^{16}$

Although OCA pupils were found throughout Zimbabwe, this survey has identified distinct "hot spots" where albinism is more common than in other areas. In particular, the prevalence value for OCA in secondary schools in Manicaland province was significantly higher than those for the neighbouring provinces of Mashonaland Central and East. The prevalence in Harare was significantly higher than in the four provinces surrounding the capital, namely the three Mashonaland provinces and the Midlands. As the Shona form the dominant ethnic group in all these provinces it is unlikely that these observed differences in prevalences reflect ethnic differences. However, it is possible that the frequency of albinism is higher in the Manyika and Ndau subgroups of the Shona people who live in Manicaland, owing to a founder effect. The Shona have lived in this region of southern Africa for around 1500 years and have shown limited mobility in the past. Random genetic drift is thus also likely to be a factor contributing to the observed differences between provinces.

As there is substantial migration from the provinces to the capital city, ethnic differences and genetic drift do not explain the significantly higher prevalence of 1 in 2833 previously documented for Harare, ${ }^{19}$ compared with the value of 1 in 4728 reported here for the provinces outside the capital. The high prevalence in Harare, where $98.4 \%$ of secondary pupils attended urban schools, is undoubtedly a reflection of the observed highly significant difference between the prevalence of OCA in urban and rural areas of Zimbabwe ( 1 in 3268 
$v 1$ in 4694). This is not true of Manicaland where only $10.3 \%$ of secondary pupils were at urban schools.

Most of the studies in Africa to determine the prevalence of albinism have concentrated on urban areas where data collection is easier than in remote rural parts. It has been suggested that children with albinism in South Africa may be sent from urban areas to live with relatives in the countryside, resulting in a lower prevalence in urban compared with rural areas. ${ }^{15}$ Recent results from a rural area in northern South Africa identified five affected babies among 7617 neonates, giving an incidence of 1 in 1523 among the northern Sotho, ${ }^{16}$ compared with a prevalence of 1 in 2041 for southern Sotho in urban Soweto, South Africa, ${ }^{15}$ suggesting that recessive genetic conditions such as albinism are at least as common in rural as in urban areas. However, the data reported here show that OCA is more prevalent in urban parts of Zimbabwe. Children with albinism may be sent to urban areas for their education, leading to a particularly high prevalence in Harare province where most pupils attended urban schools. A headmaster of a school in Mashonaland Central mentioned in his survey response that three children with OCA in his rural community were sent to Harare for their education. It is unlikely that children with albinism in rural areas are simply not sent to school. Zimbabwe encourages universal education, particularly at primary level, and heads of rural schools would probably be aware of children in their catchment area not attending school. These results indicate that data collected from urban areas alone may be biased, and may not be a true reflection of the prevalence of a genetic condition for a country as a whole.

Numerically by far the greater number of pupils with albinism were living in rural locations, 248, compared with 129 in urban areas. Affected subjects living in urban areas have access to specialist eye care units and hospitals to treat skin lesions, whereas those living in rural areas often do not. The provision of the necessary health care and information to people with albinism living in rural areas is an issue which needs to be addressed. The positive response to the information leaflets sent out to schools with affected pupils as part of this survey suggests that the school system may be one possible route of delivery of genetic information and details of how to manage the condition.
Recent molecular genetic studies have identified a common deletion allele in OCA2 subjects from various regions of Africa, including Zaire, Cameroon, ${ }^{10}$ and South Africa. ${ }^{3}$ This work is continuing to determine if this allele is also widespread among OCA2 people belonging to different ethnic groups in Zimbabwe.

This research was funded by the University of Zimbabwe. Special thanks are due to the heads, teachers, and the pupils with albinism who participated so willingly in this project and to $\mathrm{Dr}$ Mark Roberts who contributed numerous ideas.

1 Witkop CJ, Quevedo WC, Fitzpatrick TB, King RA Albinism. In: Scriver CR, Beaudet AL, Sly WS, Valle D, eds. The metabolic basis of inherited disease. 6th ed. New York: McGraw-Hill, 1989:2905-47.

2 King RA, Summers CG. Albinism. Dermatol Clin 1988; 6:217-28.

3 Stevens G, van Beukering J, Jenkins T, Ramsay $M$. An intragenic deletion of the $P$ gene is the common mutation causing tyrosinase positive oculocutaneous albinism (OCA2) in southern African Negroids. Am $\mathcal{F}$ Hum Genet 1995; in southern

4 Okoro AN. Albinism in Nigeria. Br 7 Dermatol 1975;92:48592.

5 Luande J. Henschke CI, Mohammed N. The Tanzanian human albino skin. Cancer 1985;55:1823-8.

6 Kromberg JGR, Castle D, Zwane EM, Jenkins T. Albinism and skin cancer in southern Africa. Clin Genet 1989;36:4352.

7 Kromberg JGR, Jenkins T. Albinism in the South African Negro. III. Genetic counselling issues. $\mathcal{F}$ Biosoc $\mathrm{Sc}$ 1984;16:99-108.

8 Ezeilo BN. Psychological aspects of albinism: an exploratory study with Nigerian (Igbo) albino subjects. Soc Sci Med 1989;29:1129-31.

9 Kromberg J. Albinism in the South African Negro. IV. Attitudes and the death myth. Birth Defects 1992;28:159-66.

10 Ramsay M, Colman M, Stevens G, Zwane E, Kromberg J, Farrall $M$, Jenkins $T$. The tyrosinase-positive oculocutaneous albinism locus maps to chromosome 15q11.2-q12. Am f Hum Genet 1992;51:879-84.

11 Rinchik EM, Bultman SJ, Horsthemke B, et al. A gene for the mouse pink-eyed dilution locus and for human type II oculocutaneous albinism. Nature 1993;361:72-6.

12 Lee S, Nicholls RD, Bundey S, Laxova R. Musarella M, Spritz RA. Mutations of the P gene in oculocutaneous Spritz RA. Mutations of the P gene in oculocutaneous albinism. N Engl f Med 1994;330:529-34.

13 Kedda MA, Stevens G, Manga P, Viljoen C, Jenkins T, Ramsay M. The tyrosinase-positive oculocutaneous gen shows locus homogeneity on chromosome 15 qll-ql3 and evidence of multiple mutations in southern African negroids. Am $\mathcal{F}$ Hum Genet 1994;54:1078-84.

14 Durham-Pierre D, Gardner JM, Nakatsu Y, et al. African origin of an intragenic deletion of the human $P$ gene in origin of an intragenic deletion of the humasine oculocutaneous albinism. Nature Genet tyrosinase positivi

15 Kromberg JGR, Jenkins T. Prevalence of albinism in the South African negro. $S$ Afr Med $\mathcal{f}$ 1982;61:383-6.

16 Venter PA, Christianson AL, Hutamo CM, Makbura MP, Gericke GS. Congenital anomalies in rural black South African neonates - a silent epidemic? $S$ Afr Med $f$ 1995;85:15-20.

17 Ewusie JY. Characterization of the genetic profile of Swaziland, the ABO blood groups and albinism. Swazi $\mathcal{F} S c i$ Technol 1988;9:45-55.

18 Zimbabwe National Report. Census 1992. Harare, Zimbabwe: Central Statistical Office, 1994:5.

19 Kagore F, Lund PM. Oculocutaneous albinism among schoolchildren in Harare, Zimbabwe. $f$ Med Gene 1995;32:859-61.

20 Curtin P, Feierman S, Thompson L, Vansina J. African history. London: Longman, 1978:278-84. 